\title{
OSSEOUS METAPLASIA OF CERVIX A RARE ENTITY IN PRACTICING GYNAECPATHOLOGY: A CASE REPORT
}

\author{
Srinivas N. S. Nori¹, V. Ram Mohan Rao², Sapna Vyakaranam³ ${ }^{3}$ Hema Rakesh V4, Hanuma Chitta ${ }^{5}$
}

\section{HOW TO CITE THIS ARTICLE:}

Srinivas N. S. Nori, V. Ram Mohan Rao, Sapna Vyakaranam, Hema Rakesh V, Hanuma Chitta. "Osseous Metaplasia of Cervix a Rare Entity in Practicing Gynaecpathology: A Case Report". Journal of Evolution of Medical and Dental Sciences 2015; Vol. 4, Issue 64, August 10; Page: 11253-11255,

DOI: $10.14260 /$ jemds/2015/1621

ABSTRACT: The entity of osseous metaplasia is very rare. Here we present a 42 years old woman with two normal live vaginal deliveries, referred to our gynecology outpatient clinic with dysmenorrhoea of one year duration and white discharge per vagina of four month duration. General, gynecologic and colposcopic assessments were done. A healed cervical scar was observed and an excision biopsy was performed. A diagnosis of cervical osseous metaplasia was confirmed on histological examination. It was concluded that healed and fibrosed scar could be the cause for osseous metaplasia of cervix.

KEYWORDS: Osseous metaplasia, Cervical osseous metaplasia.

INTRODUCTION: Although many locations for osseous metaplasia have been reported in the literature there were very few cases reported for osseous metaplasia of cervix among all the age groups from reproductive to menopausal. Osseous metaplasia (OM) is defined by the presence of heterotrophic normal bone tissue in a soft tissue.(1)

Overall, it occurs in approximately 0.3 per 1000 women.(2) Though numerous endometrial osteometaplasia have been reported, till date only 7 cases of cervical osteometaplasia are reported.(3) Inflammatory and traumatic processes is considered in the pathogenesis of osseous metaplasia of cervix, still its etiology remains obscure.(4) We are presenting a rare case of pathological transformation -osseous metaplasia of cervix.

CASE REPORT: A 42 year old woman came with complaints of white discharge pervagina for duration of 4 months and dysmenorrhea of one year duration. There was no history of abortions or menstrual irregularities earlier. She had two full term normal vaginal deliveries. There was no contributory history of hormones or drug intake.

On examination the cervix looked normal, but was hard and craggy on palpation and it also bled on touch. An old healed cervical tear at 11"0"clock position was identified. A high vaginal swab, ectocervical and endocervical smears were taken. An urgent colposcopic examination was organized and dilatation and curettage was also performed. Cone biopsy was performed from this area and was sent for histological examination.

Bacteriology and cytology results were unremarkable. Colposcopic examination revealed a suspicious hard lesion just at the edge of the endocervix.

Surprisingly, analysis of the hard main lesion showed that it was bone surrounded by an inflammatory exudates and severely inflamed mucosa partially covered with squamous epithelium (Figs. 1 and 2); this was consistent with a diagnosis of osseous metaplasia in the cervical epithelium. 


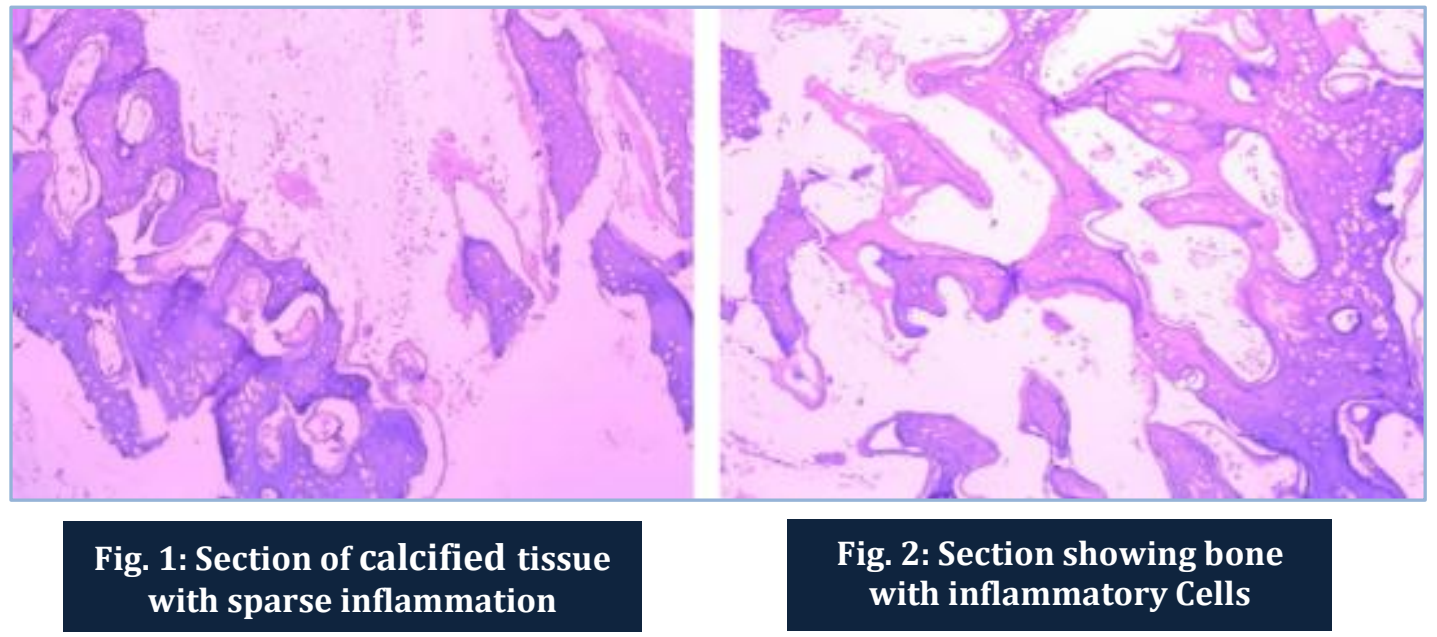

Sections from the endometrial curettings showed the features of disordered endometrium with few glands in proliferative phase, few in simple cystoglandular hyperplasia without atypia and yet a few in early secretory phase.

We further investigated and her biochemical parameters serum calcium, phosphorus, magnesium levels were within normal range, serum TSH, parathormone and electrolytes sodium, potassium, chlorides, phosphates were also in normal limits. USG abdomen was not contributory.

DISCUSSION: Osseous metaplasia of cervix, an ectopic cervical bone is a rare entity. It is a disorder of controversial etiology and unclear pathology.(5) In our case patient complained white discharge pervagina and a healed cervical tear was observed. A clinical thought of foreign body was suspected but was ruled out after the histological confirmation of osseous metaplasia. The most common theory advanced in cervical metaplasia pathogenesis is injury to the cervix either by surgical trauma or by recurrent infections.(4)(5) This causes the mesenchymal cells to transform to osteocytes. Osseous metaplasia may present with leucorrhea, vaginal bleeding, menstrual irregularities, dyspareunia, infertility and abortions.(6)(7) With this history and clinical examination this is a clear case of osseous metaplasia of cervix.

CONCLUSION: We conclude that the most likely explanation for the finding of bone in the cervix is osseous metaplasia, secondary to the inflammatory and traumatic processes brought about by healed cervical tear.

ACKNOWLEDGEMENT: I would sincerely thank Dr. Suri Srimati MD Obstetrics and gynecology, Sagarlal hospitals, Hyderabad who supported me in this publication.

\section{REFERENCES:}

1. Gal-Gombos EC, Esserman LE, Poniecka AW, Odzer SL, Weisberg S, Godinez J, et al. Osseous metaplasia of the breast: Diagnosis with stereotactic core biopsy. Breast J. 2002;8(1):50-2.

2. Coccia ME, Becattini C, Bracco GL, Scarselli G. Ultrasound-guided hysteroscopic management of endometrial osseous metaplasia. Ultrasound in obstetrics \& gynecology : the official journal of the International Society of Ultrasound in Obstetrics and Gynecology. 1996. p. 134-6. 


\section{CASE REPORT}

3. NigarA, YadavYK HS. Endometrial Osseous Metaplasia-A Rare Presentation of Polymenorrhagia: A Case Report. J Clin Diagnostic Res. 2015;9(4):8-9.

4. Sabatini L, Rainey AJ, Tenuwara W, Webb JB. Osseous metaplasia of cervical epithelium. Br J Obstet Gynaecol. 2001;108(3):333-4.

5. Mandato VD, Sacchetti F, Gelli MC LSG. A hard cervix: Microscopic examination revealed that a rare transformation had occurred. Am J Obs Gynecol. 2012;206:362. e1-3.

6. Ejeckam GC, Haseeb F, Ahamad R AB. Endometrial ossification. Trop Geogr Med. 1991; 43:314-6.

7. Polat I, Sahin O, Yildirim G, Karaman E, Erim A, Tekirdag AI. Osseous metaplasia of the cervix and endometrium: A case of secondary infertility. 2011;95(7):2434e1-e4.

\section{AUTHORS:}

1. Srinivas N. S. Nori

2. V. Ram Mohan Rao

3. Sapna Vyakaranam

4. Hema Rakesh V.

5. Hanuma Chitta

\section{PARTICULARS OF CONTRIBUTORS:}

1. Assistant Professor, Department of Pathology, Mediciti Institute of Medical Sciences.

2. Associate Professor, Department of Pathology, Malla Reddy Institute of Medical Sciences.

3. Associate Professor, Department of BioChemistry, Mediciti Institute of Medical Sciences.

FINANCIAL OR OTHER COMPETING INTERESTS: None
4. Consultant Gynaecologist and Obstetrician, Cure well Hospitals.

5. Resident Physician, Department of Internal Medicine, University of Illinois College of Medicine, Peoria, Illinois, U.S.A.

\section{NAME ADDRESS EMAIL ID OF THE} CORRESPONDING AUTHOR:

Dr. Srinivas N. S. Nori,

Flat No. 209,

M. L. APPTs, 1-8-81, Temple-Alwal, Secunderabad-500010, Telangana State.

E-mail: drsrinivasnns@gmail.com

Date of Submission: 21/07/2015.

Date of Peer Review: 22/07/2015.

Date of Acceptance: 04/08/2015.

Date of Publishing: 10/08/2015. 